\title{
The reliability of the "Iberic graft" for covering of the radial forearm free flap donor site
}

\author{
Manuel Moreno-Sánchez¹, Raúl González-García ${ }^{1,2}$ \\ ${ }^{1}$ Department of Oral and Maxillofacial-Head and Neck Surgery, University Hospital Infanta Cristina, 06080 Badajoz, Spain. \\ ${ }^{2}$ Department of Surgery, University of Extremadura, 06071 Badajoz, Spain. \\ Correspondence Author: Dr. Manuel Moreno-Sánchez, Department of Oral and Maxillofacial-Head and Neck Surgery, University \\ Hospital Infanta Cristina, Avenida de Elvas s/n, 06080 Badajoz, Spain. E-mail: manumorenosanchez@hotmail.com
}

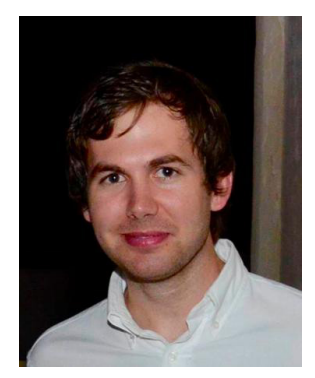

Dr. Manuel Moreno-Sánchez, M.D., obtained his Medical Degree at the University of Extremadura School of Medicine in Badajoz, Spain, in 2010. After that, he began to work as Resident Surgeon of Oral and Maxillofacial Surgery at the University Hospital Infanta Cristina, Badajoz, Spain. He is also University Honorary Collaborator at the University of Extremadura and he has completed a Master's Degree in Biomedicine. Currently, he is a postgraduate student at the Program of Modeling and Experimentation in Science and Technology of the University of Extremadura.

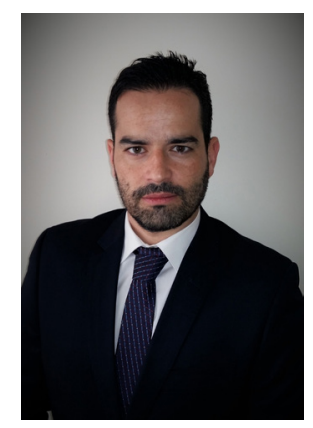

Prof. Raúl González-García, M.D., Ph.D, FEBOMFS, was graduated in Medicine (Medical Degree, M.D.) by the Universidad Autónoma de Madrid School of Medicine, Madrid, Spain, in 2001, and obtained his trainee in Oral and Maxillofacial Surgery in the University Hospital La Princesa, Madrid, Spain, in 2007. He obtained his Ph.D. Degree in Medicine and Surgery at the Universidad Autónoma de Madrid School of Medicine, in 2011. Since 2007 he is Consultant Surgeon at the Department of Oral and Maxillofacial Surgery, University Hospital Infanta Cristina, Badajoz, Spain, and he is also a University Honorary Collaborator at the Universidad de Extremadura School of Medicine. He is actually Editor-in-Chief of Plastic and Aesthetic Research, Assistant Director of Revista Española de Cirugía Oral y Maxilofacial, Permanent Member of the Reviewer Commitee of International Journal of Oral and Maxillofacial Surgery, Contributing Editor of Current Research in Dentistry, and Member of the Editorial Board/reviewer of more than 35 international journals of the speciality. He is author of more than 130 publications, 96 of them in international Medline/PubMed-indexed journals, 15 chapters in books of the speciality, and he is author of the text book "Reconstrucción Maxilomandibular Compleja: Microcirugía, Distracción Ósea e Implantes dentales".

\begin{abstract}
Aim: Traditional donor site closure from radial forearm free flap (RFFF) has been associated with esthetic and functional morbidity. To avoid complications, such as color mismatch and secondary donor site morbidity, a new technique named "Iberic graft" for covering the RFFF donor site was described previously by our team. Methods: A study of patients who underwent reconstruction of head and neck defects using a RFFF was conducted to assess postoperative complications of the RFFF donor site and also to evaluate the morbidity in terms of aesthetics and function following the use of the "Iberic graft". The donor site was covered by the use of
\end{abstract}

\begin{tabular}{|l|l|}
\hline \multicolumn{2}{|c|}{ Access this article online } \\
\hline Quick Response Code: & Website: \\
& http://www.parjournal.net \\
& \\
&
\end{tabular}

This is an open access article distributed under the terms of the Creative Commons Attribution-NonCommercial-ShareAlike 3.0 License, which allows others to remix, tweak and build upon the work non-commercially, as long as the author is credited and the new creations are licensed under the identical terms.

For reprints contact: service@oaepublish.com

How to cite this article: Moreno-Sánchez M, González-García $\mathrm{R}$. The reliability of the "Iberic graft" for covering of the radial forearm free flap donor site. Plast Aesthet Res 2016;3:197-202.

Received: 04-04-2016; Accepted: 02-06-2016 
a combined local triangular full-thickness skin graft. Color match, quality of the scar, presence of necrosis, dehiscence of the suture or tendon exposure were recorded and analyzed. Results: One hundred and twenty-five consecutive patients undergoing RFFF harvesting were included. RFFF donor site defects ranged from $15 \mathrm{~cm}^{2}$ to $70 \mathrm{~cm}^{2} ; 9$ patients $(7 \%)$ had small dehiscences of the forearm skin graft, whereas 2 cases $(1.6 \%)$ presented tendon exposure. Otherwise, partial skin graft loss occurred in a few patients. In all cases, these sites healed secondarily by conservative management, with no final impairment of function. Assessment of the forearm donor site at 1 to 3 months after the primary surgical procedure showed complete defect coverage, good color match, and no scarring along the graft line. Conclusion: The "Iberic graft" is a reliable method for closing most of RFFF donor site defects as it provides excellent color match and pliability, while obviates the need for a second surgical site.

Key words:

Radial forearm free flap; donor site morbidity; full-thickness skin graft; "Iberic graft"

\section{INTRODUCTION}

Since its introduction in 1981 by Yang et al.$^{[1]}$ the radial forearm free flap (RFFF) has been used extensively for reconstruction of head and neck defects after oncologic resection. However, many donor site complications have been described, such as partial loss of the skin graft, sensory disturbance, tendon exposure, and esthetic pitfalls. ${ }^{[2-5]}$ Direct closure is not often possible due to toolarge defects or insufficient skin laxity. ${ }^{|6-8|}$

Several techniques have been described for adequate closure of the donor site defect after RFFF harvesting, such as purse-string closure, ${ }^{[9]}$ split-thickness skin grafts (STSGs), ${ }^{[10,11]}$ full-thickness skin grafts (FTSGs), ${ }^{\mid 12-15]}$ tissue expansion, ${ }^{[16,17]}$ closure with local flaps, ${ }^{[18-20]}$ crosssuturing, ${ }^{\mid 21]}$ use of artificial dermis, ${ }^{[22,23]}$ and local fascial flaps. ${ }^{[24]}$ STSGs are most commonly used. FTSGs can be used to provide a thicker coverage of the defect; they are more resistant to contractures or trauma and provide better esthetics results. However, their main disadvantages are potential increased morbidity and occasional need for an STSG to close the second donor site. ${ }^{|25|}$ Those patients in whom the skin graft is harvested from the thigh can develop several other complications, such as pain, infection, and hypertrophic scar formation. Moreover, evident color mismatch is often present in relation to the surrounding forearm skin. ${ }^{[26]}$ In addition, avoiding a second surgical site might be a valuable aspect to consider to decrease postoperative complication rates.

To avoid complications at the donor site from RFFF harvesting, such as color mismatch and secondary donor site morbidity, a new technique named "Iberic graft" for covering the RFFF donor site based on the use of combined local FTSG triangles within a geometric model concept was described by the authors' group in 2009..$^{[27]}$

Since its description, we have used this technique for covering the RFFF donor site in 125 patients. In this article, we analyzed the results (esthetics and function) using the Iberic graft.

\section{METHODS}

As described by González-García et al., ${ }^{[27]}$ the design of the RFFF begins by outlining the course of the dominant subcutaneous veins and the palpable pulse of the radial artery. The flap is elevated in a subfascial layer in a few cases and in a supra-fascial layer in other cases. The superficial branch of the radial nerve is preserved in all cases. The basis for the design of the Iberic graft is the geometric concept of the designed skin paddle and the local FTSGs. Thus, a quadrangular or rectangular radial forearm flap is outlined on the distal forearm. A double curvilinear line is outlined from the proximal portion of the RFFF to the proximal forearm to provide Access to the proximal portion of the neurovascular pedicle; this double curvilinear line allows the design of 2 opposed arcs. Then, 2 bowstrings are outlined within the concavities of the arcs. At the midpoint of each bowstring, a perpendicular dotted line is outlined to the midpoint of each arc. This perpendicular dotted line is half the width of the RFFF donor defect and no longer than $3.5 \mathrm{~cm}$ to allow direct closure of the forearm skin flaps. At this point, 4 isosceles triangles are depicted [Figure 1]. Subsequent triangular FTSGs are harvested and freed from the forearm. Silk sutures are used to join the FTSGs to the borders of the defect and resorbable sutures are used to join 1 skin triangle to another. Then, the FTSGs are covered with a sponge using a tie-bolster technique and dressed with regular gauzes with nitrofuran (Furacin ${ }^{\circledR} 2 \mathrm{mg} / \mathrm{g}$; LABSEID $^{\circledR}$, Barcelona, Spain) and protected in a forearm splint for 10 days.

\section{RESULTS}

One hundred and twenty-five consecutive patients underwent RFFF harvesting for head and neck reconstruction since the first case. Primary closure of 


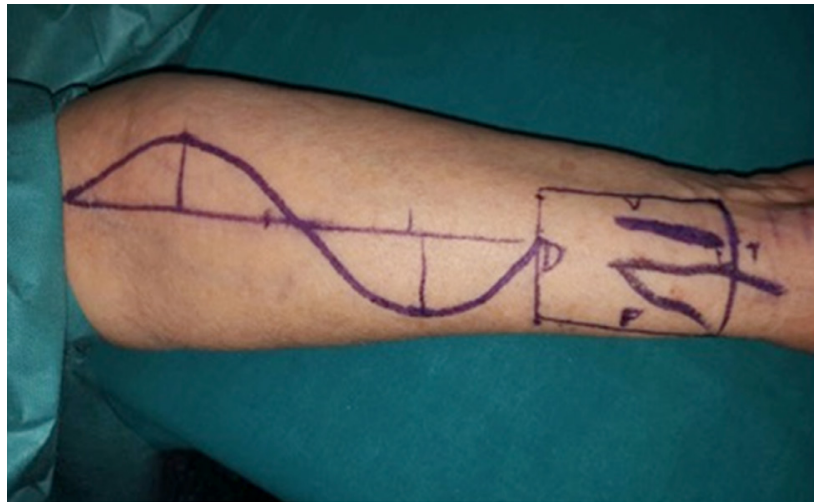

Figure 1: Design of the combined local triangular full-thickness skin graft based on 4 skin triangles for rectangular defects

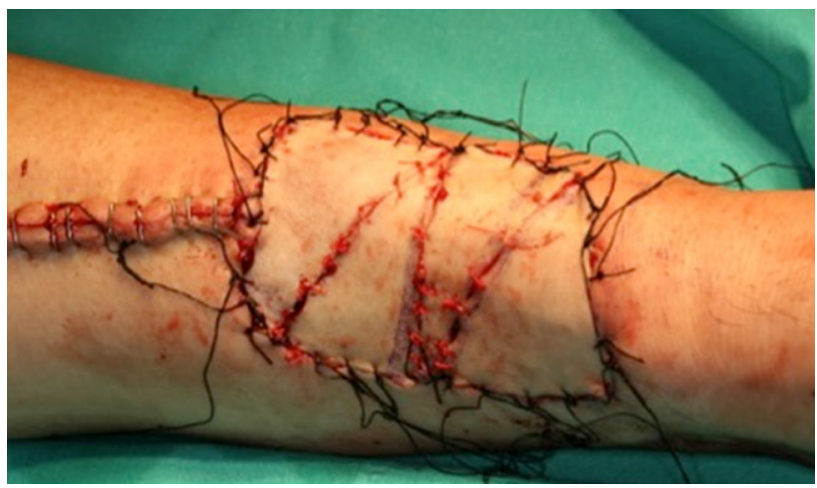

Figure 2: Postoperative clinical views of donor site. Horizontal design with 4 triangles

the donor site was achieved in allcases using the Iberic graft technique.

This technique allows covering big-sized defects using skin grafts extracted from the donor site, obtaining the same color of it. In the series of 125 patients, the RFFF donor site defects ranged from $15 \mathrm{~cm}^{2}$ to $70 \mathrm{~cm}^{2}$ (mean \pm $24.5 \mathrm{~cm}^{2}$ ). Most patients underwent reconstruction with 4 skin triangles [Figure 2], whereas coverage of the RFFF donor site with 2 or 3 skin triangles was carried out for smaller defects [Figure 3]. The versatility of this technique allows using either triangle-shaped or crescent-shaped grafts, as convenient for a proper closure.

Concerning complications of the radial donor site, only a few patients developed partial necrosis of the FTSG [Figure 4] that was treated with local debridement and healed successfully by secondary intention. No patients developed complete necrosis of the graft. Only two cases presented tendon exposure. In all cases, these sites healed secondarily by conservative management, with no final impairment of wrist mobility. No acute ischemia or compartment syndromes were encountered using this technique.

Complete healing typically occurred for 2 to 3 weeks, with the longest healing time taking approximately 2 months. Although no specific functional tests were applied, no

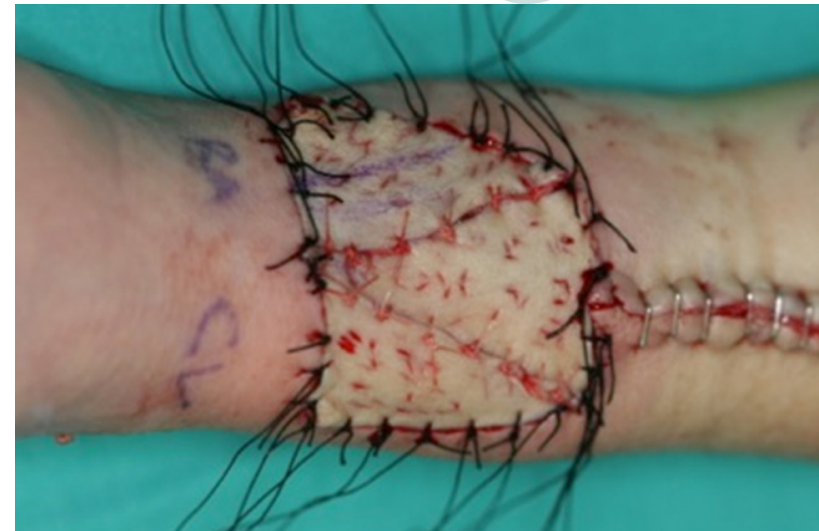

Figure 3: Reconstruction of radial forearm free flap donor site defect with 3 triangles (vertical design)

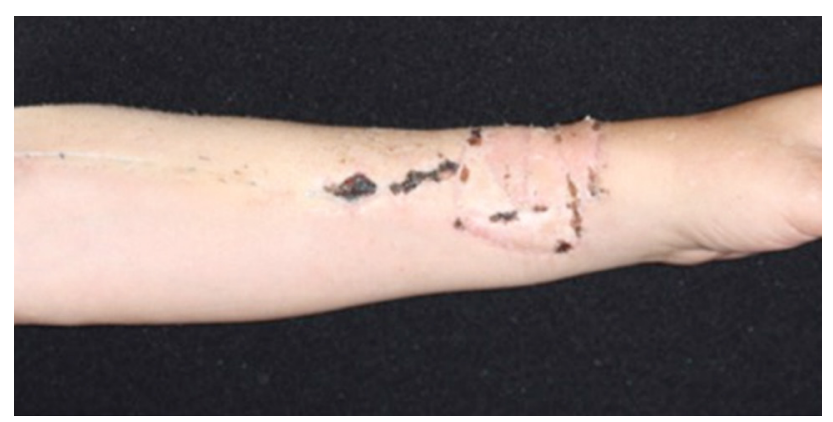

Figure 4: Partial necrosis of the full-thickness skin graft

patients complained of symptoms related to motion or any other functional deficit. No prolonged hand swelling was found. Assessment ofthe forearm donor site at 1 to 3 months after the primary surgical procedure showed complete defect coverage, good color match, and no scarring along the graft line [Figures 5-7].

\section{DISCUSSION}

Several methods for closure of the RFFF donor site have been described, most of which are based on theuse of an STSG or an FTSG. ${ }^{[12]}$ Because of its ease in harvesting and use, the STSG has been the most frequently used method of reconstruction, although several complications such as partial skin graft loss, flexor tendon exposure, and postoperative painand discomfort have been reported. ${ }^{[9]}$

The use of FTSG combined with a direct closure of the FTSG donor site has been reported to provide better pliability and promotion of the healing process, together with less postoperative pain and discomfort from the donor site, although it is more time-consuming and requires additional intraoperative processing of the graft. ${ }^{[28-31]}$ However, it is used for closure because it provides a thicker base to prevent wound breakdown and a superior esthetic result. ${ }^{[32]}$ This is the main reason for the use of this kind of grafting by the authors. 


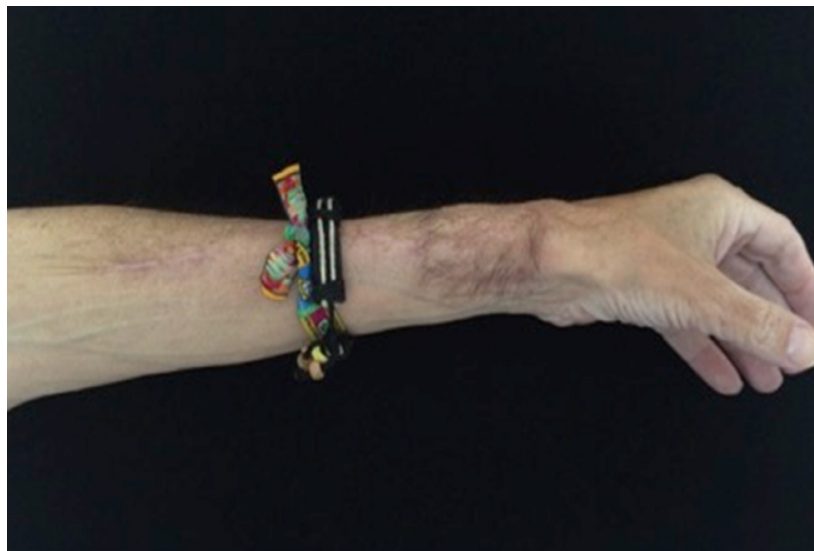

Figure 5: Good color match and esthetic outcome six months after surgery

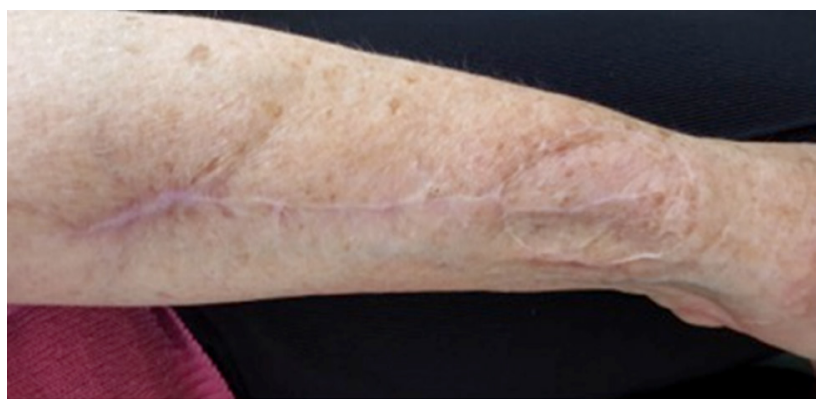

Figure 6: Good color match and esthetic outcome two months after surgery

FTSGs harvested from the abdomen for donor site closure have been used and several complications have been observed, including hematomas, postoperative pain, delayed healing, poor esthetic results, and the need for a second surgical site. ${ }^{[27]}$ An FTSG from the inner arm has been used by other investigators, but they claim that additional time for removal of the tourniquet and further preparation and draping of the arm are required. ${ }^{[33,34]}$ Other authors have recently reported the use of FTSGs harvested from the upper inner arm or neck for closure of the RFFF donor site defect, leading to a robust coverage. ${ }^{[35,36]}$ Among 25 RFFFs used for soft tissue reconstruction, Kaltman et al. ${ }^{[35]}$ found donor site morbidity in only 1 case, which had a failed FTSG. They promoted the use of a technique similar to the one proposed by Avery et al., ${ }^{[14]}$ which involves obtaining an FTSG from the inner arm to close the defect remaining from the RFFF harvesting. However, they also reported wound dehiscence at the medial arm donor site in 2 patients. Hanna et al., ${ }^{[36]}$ in a series of 50 patients who underwent RFFF reconstruction with repair of the donor site using an FTSG harvested along the neck dissection incision, reported minor skin loss in 15 cases (30\%), which was managed with local wound care until healing by secondary intention. None of the patients had recipient site infections. With this method, the need for this second surgical site was eliminated. However, this technique can be used only when the 200

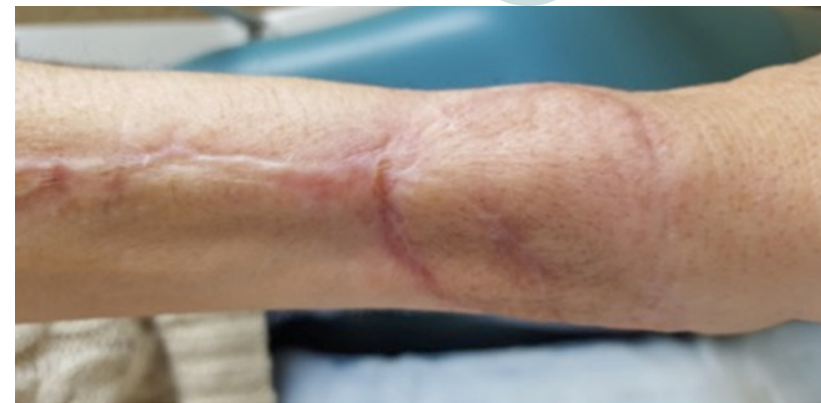

Figure 7: Good color match three months after surgery

recipient vessels are in the neck (it is not possible to use when anastomosis is performed with temporal vessels in non-oncologic patients). In the authors' opinion, another drawback with the use of an FTSG from the arm or neck for RFFF donor site reconstruction is the color mismatch in relation to the forearm skin. Several investigators have reported good results in associated morbidity for the RFFF donor site. ${ }^{[8,29,37,38]}$ However, some reported methods for covering a donor site defect are limited by the size of the defect.

As we described in the first 100 cases, ${ }^{[39]}$ the Iberic graft technique using 2 , 3 , or 4 local FTSG triangles facilitates the development of a geometricmodel for the reconstruction of large RFFF donor site defects (70 to $80 \mathrm{~cm}^{2}$ ), because the alignment of triangles with bases measuring up to $3.5 \mathrm{~cm}$ covers defects up to $7 \mathrm{~cm}$ wide. The length of the defect is not usually a problem, because defects up to $10 \mathrm{~cm}$ in length can be easily covered by triangles measuring up to $5 \mathrm{~cm}$ in height, without the need for additional extension of the forearm incision. A limitation to consider in this technique was related to moderate skin laxity of the patients, because most were 55 to 60 years old and thus more likely to achieve good results in the defect closure than younger patients with mild skin laxity. Nonetheless, this surgical technique has shown optimal results in young patients.

During the 7 years since the first description of the technique in 2009, the Iberic graft technique has been performed by the authors in every single patient undergoing reconstruction with an RFFF. Interestingly, there has been an evolution of the adaptation of the skin triangles in the donor site defect from a rigid horizontal disposition of the triangles in the very beginning to a more adaptable and flexible adaptation of the triangle skin grafts, depending on the size, shape, and contour of the donor site defect, including a proximal-to distal disposition of the grafts in the wrist to an oblique or irregular disposition. This feature also illustrates the versatility of this evolving technique for closure of RFFF donor site defects. ${ }^{[40]}$

In conclusion, the Iberic graft technique is a reliable method for closing RFFF donor site defects because 
it provides several advantages compared with other methods: (1) it provides an easy and fast way for closure of the donor site defect; (2) it is a 1-stage procedure that does not need further revision or care; (3) it obviates a second surgical site and subsequent distant donor site complications or sequela; (4) it provides an excellent color match and pliability, similar to that of the surrounding skin, because it is an FTSG harvested from the neighboring forearm skin; and (5) it can be used to cover large defects of the donor site, ensuring an adequate amount of available skin and decreasing the risk for scaring tissue. More clinical series must be reported worldwide to support the suitability of this technique in the optimal covering of RFFF defects.

\section{Financial support and sponsorship} Nil.

\section{Conflicts of interest}

There are no conflicts of interest.

\section{REFERENCES}

I. Yang GF, Chen PJ, Gao YZ, Liu XY, Li J, Jiang SX, He SP. Forearm free skin flap transplantation: a report of 56 cases. Br J Plast Surg 1981;50:162-5.

2. Soutar DS, Scherer LR, Tanner NS, McGregor IA. The radial forearm flap: a versatile method for intra-oral reconstruction. Br J Plast Surg 1983;36:1-8.

3. Soutar DS, McGregor IA. The radial forearm flap for intraoral reconstruction: the experience of 60 consecutive cases. Plast Reconstr Surg 1986;78:1-8.

4. Futran ND, Gal TJ, Farwell DG. Radial forearm free flap. Oral Maxillofac Surg Clin North Am 2003; I5:577-9I.

5. Swanson E, Boyd JB, Manktelow RT. The radial forearm flap: reconstructive applications and donor-site defects in 35 consecutive patients. Plast Reconstr Surg 1990; 85:258-66

6. Richardson D, Fisher SE, Vaughan ED, Brown JS. Radial forearm flap donor-site complications and morbidity: a prospective study. Plast Reconstr Surg 1997;99:109-15

7. Chen CM, Lin GT, Fu YC, Shieh TY, Huang IY, Shen YS, Chen CH Complications of free radial forearm transfers for head and neck reconstruction. Oral Surg Oral Med Oral Pathol Oral Radiol Endod 2005;99:67|-6.

8. Elliot D, Bardsley AF, Batchelor AG, Soutar DS. Direct closure of the radial forearm flap donor-site. Br J Plast Surg 1988;4 I:358-60.

9. Winslow CP, Hansen J, Mackenzie D, Cohen JI, Wax MK. Pursestring closure of radial forearm fasciocutaneous donor sites. Laryngoscope 2000; I10:1815-8.

10. Sidebottom AJ, Stevens L, Moore M, Magennis P, Devine JC, Brown JS, Vaughan ED. Repair of the radial free flap donor site with full or partial thickness skin graft: a prospective randomized controlled trial. Int J Oral Maxillofac Surg 2000;29:194-7.

II. Boahene K, Richmon J, Byrne P, Ishii L. Hinged forearm split-thickness skin graft for radial artery fasciocutaneous flap donor site repair. Arch Facial Plast Surg 201 I; 13:392-4.

12. Sleeman D, Carton AT, Stassen LF. Closure of radial forearm free flap defect using full-thickness skin from the anterior abdominal wall. $\mathrm{Br} \mathrm{J}$ Oral Maxillofac Surg 1994;32:54-5.

13. Liang MD, SwartzWM, Jones NF. Local full-thickness skin graft coverage for the radial forearm flap donor-site. Plast Reconstr Surg 1994;93:62 I5 .

14. Avery CM, labal M, Orr R, Hayter JP. Repair of radial free flap donor site by full-thickness skin graft from inner arm. Br J Oral Maxillofac Surg 2005;43:16|-5.
15. Kim TB, Moe KS, Eisele DW, Orloff LA, Wang SJ. Full-thickness skin graft from the groin for coverage of the radial forearm free flap donor site. Am J Otolaryngol 2007;28:325-9.

16. Berge SJ,Wiese KG, von Linderen J], Niederhagen B,Appel T, Reich RH. Tissue expansion using osmotically active hydrogel systems for direct closure of the donor defect of the radial forearm flap. Plast Reconstr Surg 201 I; 108: I-5.

17. Bonaparte JP, Corsten MJ, Odell M, Gupta M, Allen M, Tse D. Management of the radial forearm free flap donor site using a topically applied tissue expansion device. Oral Surg Oral Med Oral Pathol Oral Radiol 2013; I 16:28-34.

18. Hui KC, Zhang F, Lineaweaver WC. Z-plasty closure of the donor defect of the radial forearm free flap. J Reconstr Microsurg 1999; 15:19. 21 .

19. Akyurek M, Safak T. Direct closure of radial forearm free-flap donor sites by double-opposing rhomboid transposition flaps. J Reconstr Microsurg 2002; 18:33-6.

20. Lane JC, Swan MC, Cassell OC. Closure of the radial forearm donor site using a local hatchet flap: analysis of 45 consecutive cases. Ann Plast Surg 2013;70:308-12

21. Moazzam A, Gordon DJ. Cross-suturing as an aid to wound closure: a prospective randomized trial using the forearm flap donor site as a model. Br J Plast Surg 2003;56:695-00

22. Sinha UK, Shih C, Chang K, Rice DH. Use of AlloDerm for coverage of the radial forearm free flap donor site. Laryngoscope 2002; I I 2:230-4.

23. Wester JL, Pittman AL, Lindau RH, Wax MK. AlloDerm with splitthickness skin graft for coverage of the forearm free flap donor site. Otolaryngol Head Neck Surg 2014; I50:47-52.

24. Lutz BS, Wei FC, Chang SC, Yang KH, Chen IH. Donor site morbidity after suprafascial elevation of the radial forearm flap: a prospective study in 95 consecutive cases. Plast Reconstr Surg 1999; I03:132-7.

25. Rowe NM, Morris L, Delacure MD. Acellular dermal composite allografts for reconstruction of the radial forearm donor site. Ann Plast Surg 2006;57:305-II.

26. Ho T, Couch M, Carson K, Schimberg A, Manley K, Byrne PJ. Radial forearm free flap donor site outcomes comparison by closure methods. Otolaryngol Head Neck Surg 2006; I 34:309-I5.

27. González-García R, Ruiz-Laza L, Manzano D, Moreno C, Maestre O, Serrano H, Villanueva L, Monje F. Combined local triangular fullthickness skin graft for the closure of the radial forearm free flap donor site: a new technique.J Oral Maxillofac Surg 2009;67:I562-7.

28. Karimi A, Mahy P, Reychler $\mathrm{H}$. Closure of the radial forearm free flap donor site defect with a local meshed full-thickness skin graft: a retrospective study of an original technique. J Craniomaxillofac Surg 2007;35:369-73

29. Zuidam JM, Coert JH, Hofer SO. Closure of the donor site of the free radial forearm flap: a comparison of full- thickness graft and splitthickness graft. Ann Plast Surg 2005;55:6 I 2-6.

30. Lee JW, Jang YC, Oh SJ. Use of the artificial dermis for free radial forearm flap donor site. Ann Plast Surg 2005;55:500-2.

31. Pandya AN, Vadodaria S, Coleman DJ. Tissue expansion in the limbs: a comparative analysis of limb and non-limb sites. Br J Plast Surg 2002;55:302-6

32. Gaukroger MC, Langdon JD,Whear NM, Zaki GA. Repair of the radial forearm flap donor site with a full-thickness graft. Int J Oral Maxillofac Surg 1994;23:205-8.

33. Médard de Chardon V, Balaguer T, Chignon-Sicard B, Riah Y, Ihrai T, Dannan E. The radial forearm free flap: a review of microsurgical options.J Plast Reconstr Aesthet Surg 2009;62:5-10.

34. van der Lei B, Spronk CA, de Visscher JG. Closure of radial forearm free flap donor site with local full-thickness skin graft. $\mathrm{Br} J$ Oral Maxillofac Surg 1999;37: I 19-22.

35. Kaltman JM, McClure SA, Lopez EA, Pedroletti F. Closure of the radial forearm free flap donor site defect with a full-thickness skin graft from the inner arm: a preferred technique. J Oral Maxillofac Surg 2012:70:1459-3.

36. Hanna TC, McKenzie WS, Holmes JD. Full-thickness skin graft from the neck for coverage of the radial forearm free flap donor site.J Oral Maxillofac Surg 2014;72:2054-9. 
37. Shiba K, lida Y, Numata T. Ipsilateral full-thickness forearm skin graft for covering the radial forearm flap donor site. Laryngoscope 2003; I I3:1043-6

38. Jaquet $Y$, Enepekides DJ, Torquerson C, Higgins KM. Radial forearm free flap donor site morbidity: ulnar-based transposition flap vs. splitthickness skin graft. Arch Otolaryngol Head Neck Surg 20I2;138:38-43.
39. Moreno-Sánchez M, González-García R, Ruiz-Laza L, Manzano Solo de Zaldívar D, Moreno-García C, Monje F. Closure of the radial forearm free flap donor site using the combined local triangular full-thickness skin graft. J Oral Maxillofac Surg 2016;74:204-I I.

40. González-García R. Local full-thickness skin graft to cover the radial forearm free flap donor site. Int J Oral Maxillofac Surg 2016;45:132-3. 